\title{
Factors affecting economics of using sexed semen in dairy cattle
}

\author{
Katelyn McCullock, ${ }^{\star}$ Dana L. K. Hoag, $\dagger^{1}$ Jay Parsons, $†$ Michael Lacy, $\ddagger$ George E. Seidel Jr.,§ \\ and William Wailes\# \\ *Livestock Marketing Information Center, \\ †Department of Agricultural and Resource Economics, \\ ‡Department of Sociology, \\ $\S$ Department of Biomedical Sciences, and \\ \#Department of Animal Sciences, Colorado State University, Fort Collins 80523
}

\begin{abstract}
The use of sexed semen in the dairy industry has grown rapidly. However, high costs and low fertility have limited the use of this potentially valuable tool. This study used simulation to evaluate 160,000 combinations of key variables in 3 spheres of influence related to profit feasibility: (1) market (e.g., milk and calf prices), (2) dairy farm management (e.g., conception rates), and (3) technology (e.g., accuracy of sexing). These influential variables were used to determine the most favorable circumstances in which managers or technicians can effect change. Three distinct scenarios were created to model 3 initiatives that a producer might take with sexed semen: (1) using sexed semen on heifers, (2) using sexed semen on heifers and a fraction of the genetically superior cows, and (3) using sexed semen on heifers and a fraction of the genetically superior cows, and breeding all other cows with beef semen. Due to the large number of management, market, and technology combinations, a response surface and interpretive graphs were created to map the scope of influence for the key variables. Technology variables such as the added cost of sexed semen had relatively little effect on profitability, defined as net present value gain per cow, whereas management variables such as conception rate had a significant effect. Milk price had relatively little effect within each scenario, but was important across scenarios. Profitability was very sensitive to the price of dairy heifer calves, relative to beef and dairy bull calves. Scenarios 1 and 2 added about $\$ 50$ to $\$ 75$ per cow in net present value, which ranged from $\$ 0$ to $\$ 200$ and from $\$ 100$ to $\$ 300$, respectively. Scenario 3 usually was not profitable, primarily because fewer excess dairy replacement heifers were available for sale. Dairy heifer price proved to be the most influential variable, regardless of scenario.
\end{abstract}

Received February 7, 2013.

Accepted June 14, 2013.

${ }^{1}$ Corresponding author: dhoag@colostate.edu
Key words: dairy cattle, economics, feasibility, sexed semen

\section{INTRODUCTION}

Adoption of sexed semen for AI in cattle has been limited by cost, low conception rates, and sexing accuracy. Technology has improved by increasing sorting rates, conception rates have increased over the past decade, sexing accuracy is near 90\% (Schenk et al., 2009), and the premium for sexed semen is often below $\$ 20$ per dose (roughly doubling the cost of semen). Consequently, the dairy industry is increasingly taking advantage of this innovative and unique technology. However, many questions emerge about which market, production, and other circumstances result in a sexed semen advantage (SSA) - increased profit compared with using conventional semen. The purpose of this research was to identify those circumstances.

Sexed semen advantage is a function of interactions among 3 spheres of influence: the market environment (e.g., prices and costs), management practices (e.g., breeding program), and technological efficiency (e.g., accuracy of sexing semen). Managers and technology providers can alter their practices; the market environment is given. Previous studies have examined the influence of variables in all 3 spheres: markets, such as milk or heifer prices (De Vries et al., 2008); management changes (Olynk and Wolf, 2007); and technology changes (Seidel and Garner, 2002). These studies provided valuable information about the economics of sexed semen, but focused on likely scenarios regarding prices and technology. No one to our knowledge has explored the implications of using sexed semen over a wider range of possibilities in input and output prices, technologies, and management options that can and do occur in the highly dynamic and volatile dairy industry. Studies have also not identified the scope of impact that decision makers have when they can control only variables in 1 of the 3 spheres of influence. That is, how much can a manager do when the technology and 
market are given? Likewise, can technological improvements help when the market is given and managers have to respond accordingly?

The spheres organize variables into decision maker groups that can be used to determine which has the best chance of making a difference in SSA. Imagine each sphere as a single circle in a Venn diagram such as that shown in Figure 1, with regions of overlap where the technology is feasible (SSA is positive). Figure 1a portrays non-overlapping circles, which indicates infeasibility over all variable ranges. Changes in any sphere will not create a positive investment, and nothing managers or technologists do, given the current market conditions, will make sexed semen profitable. Figure 1c, in which all 3 circles coincide completely, illustrates conditions in which sexed semen is profitable over all variable ranges. In this case, managers or technologists can make changes with no concern of making sexed semen unprofitable. Figure 1b describes overlapping circles, illustrating that sexed semen is economically feasible under some conditions, which possibly can be controlled.

This research was undertaken to determine environmental, management, and technology conditions where sexed semen would be profitable. Potentially hundreds of variables exist that could have an effect on the profitability of sexed semen, and several management scenarios that a producer might pursue. A wide range of values were considered for 13 key variables and 3 management scenarios, and then mapped into a response surface. This is consistent with other studies that have investigated the profitability of sexed semen, but potentially more robust, as the response surface indicates the profitability of sexed semen given any combination of the key variables that would conceivably occur. Olynk and Wolf (2007), for example, varied management variables, such as conception rate and number of inseminations, and scenarios, such as the number of animals, to describe situations in which a farmer could invest in sexed semen. Seidel and Garner (2002) and Seidel (2003) suggested that sexed semen enables a dairy producer to more efficiently produce better-quality replacement heifers, as genetically superior animals can be selected to produce female herd replacements with 90\% certainty. Hohenboken (1999) suggested combining sexed semen with a crossbreeding program to maximize revenue from the herd's nonreplacement calves. De Vries et al. (2008) took a more macroscopic view, considering the impact of sexed semen adoption on the fluctuation of industry prices. Finally, the key variables were divided into 3 decisionmaking regions (Figures 1a, 1b, and 1c) to identify the ability of any single decision maker to affect profitability, given decisions made in the other 2 regions.

\section{MATERIALS AND METHODS}

Our approach was to build enterprise budgets that could accommodate a sensitivity analysis of key input variables and management scenarios found to be important in previous studies, and use those budgets to determine conditions in which sexed semen might be

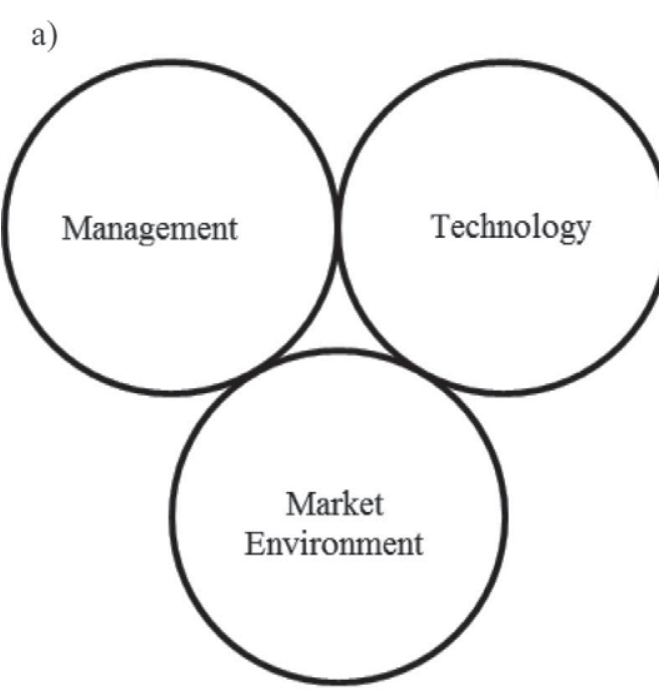

Region A: Infeasibility b)

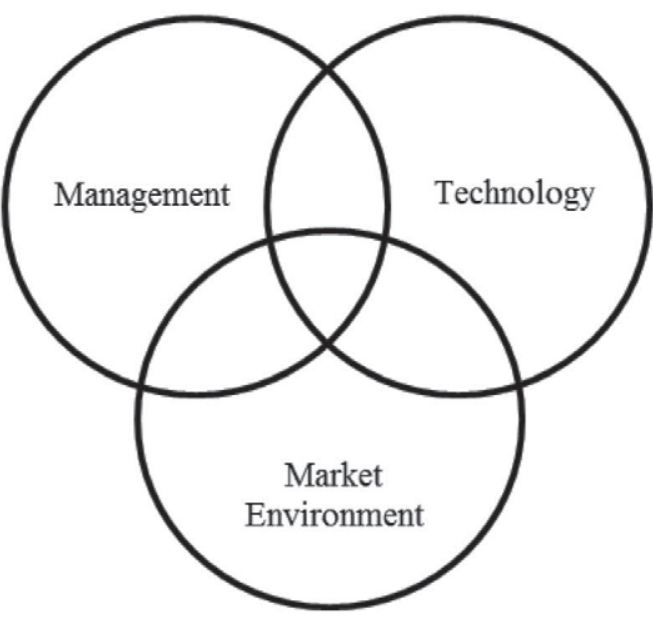

Region B: Conditional Feasibility c)

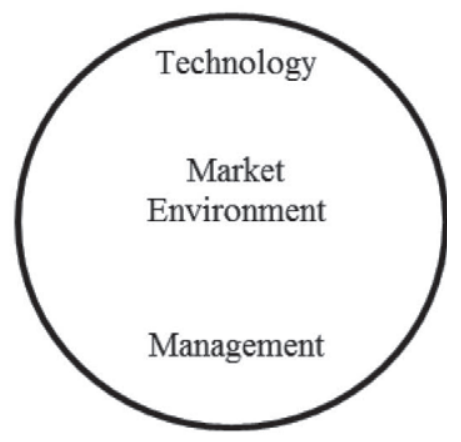

Region C: Feasibility

Figure 1. Venn diagrams of management, technology, and market spheres of influence over sexed semen feasibility. 
Table 1. Breeding scenarios used with sexed semen

\begin{tabular}{lll}
\hline Scenario & Sexed semen use & Semen type on remaining animals \\
\hline Scenario 1 & First-calf heifers only & Conventional dairy semen \\
Scenario 2 & First-calf heifers and enough cows to cover replacement needs & Conventional dairy semen \\
Scenario 3 & First-calf heifers and enough cows to cover replacement needs & Conventional beef semen \\
\hline
\end{tabular}

more profitable than conventional semen. The analysis involved 4 key steps: (1) identify likely management scenarios, (2) build a budget model, (3) conduct a sensitivity analysis, and (4) regress a response surface and develop an interpretive tool that summarizes the response surface. The management scenarios and budget model were based on available literature and experience of 2 of the authors who own dairy cattle. The response surface used Monte Carlo simulations, as too many combinations of variables existed to explore (e.g., Leuer et al., 2008; Herbst et al., 2009; Khanal and Gillespie, 2011). The response surface was developed to make it easier to find combinations of variables that favor sexed semen. We also added a graphical interpretive tool (called variable feasibility maps) that simplified the regression results by showing the ranges for each key variable that placed a producer in the regions illustrated in Figure 1.

\section{Scenarios}

Situations in which sexed semen appear to be used include herd expansion through internal growth and increasing the value of nonreplacements with constant herd size. Constant herd size and increasing the value of animals not needed for replacements were chosen for this study. A baseline, or control scenario, assumed that cattle were inseminated artificially with conventional semen. Three management scenarios were created to take advantage of using sexed semen while keeping herd size constant (Table 1). In the first scenario, sexed semen is used to produce replacements, but its use is targeted to heifers only. The higher conception rates associated with heifers partially compensates for conception rates that are lower for sexed than conventional semen (DeJarnette et al., 2008; Schenk et al., 2009; Norman et al., 2010). In scenario 2, heifers and genetically superior cows were bred with sexed semen to produce replacements; cows producing nonreplacement calves were inseminated with conventional dairy semen. In scenario 2 , the deficiency in heifer replacements from breeding heifers is made up with cows also bred with sexed semen. Finally, in scenario 3, heifers and genetically superior cows were bred with sexed semen for replacements, with conventional beef semen used for cows not needed to produce replacement calves, allowing the producer to switch markets when dairy calf prices are low relative to beef calves.

\section{Budget Model}

The initial cost and profit analysis was based on a spreadsheet budget for a baseline farm (control), with provisions to implement any of the other scenarios. Selected basic characteristics of a typical 2,500-head Colorado Holstein dairy are shown in Table 2. Reproduction practices for cows included synchronizing ovulation with an Ovsynch protocol (e.g., Martins et al., 2011). For heifers, a fixed-time AI protocol was anticipated (e.g., http://www.dcrcouncil.org/media/Public/ Dairy\%20Heifer\%20Protocol\%20sheet.pdf). Cows and heifers that failed to achieve pregnancy were rebred until pregnant or culled. It was assumed cows would be culled if not conceiving by the seventh service and heifers by the fourth service. For both cases, about 5\% are culled for infertility with these endpoints. The herd was broken down into 3 lactation groups: lactations 1 , 2 , and 3 or more.

Key Input Variables. Over 75 variables were in the final farm budget model, including those variables added for sexed semen. A systematic approach was developed to narrow the scope of analysis to find key variables that affect the feasibility of using sexed semen in 1 of our 3 scenarios. First, variables were grouped into 4 categories, 3 relating to spheres of influence (market variables, technology variables, and management variables) and a fourth "other" category. The fourth category included farm practices, characteristics, and biological variables that were set as fixed parameters for purposes of the analysis and are shown in Table 2. Although setting the fourth category as parameters helped shrink the number of variables, a large number of variables still existed in each sphere. The second step was to focus on variables in each sphere that had the greatest potential marginal impact on profitability per cow. A sensitivity analysis was conducted with respect to profit. Variables with the highest change in profit were identified as key input variables for the respective sphere. In addition, a few variables were retained regardless of their marginal impact on profit because they were speculated to be important in the literature or by our experience (G. E. Seidel and W. Wailes). 
Table 2. Assumed characteristics of the baseline Colorado dairy farm ${ }^{1}$

\begin{tabular}{|c|c|}
\hline Parameter & Value \\
\hline Number of cows & 2,500 \\
\hline Percent in lactations 1,2 , and 3 & $35,28,37$ \\
\hline Ovsynch use, cows; fixed-time AI protocol for heifers (\%) & 100 \\
\hline Percent bred & 100 \\
\hline Sex ratio, conventional semen $(\%)$ & 50 \\
\hline Cull rate, heifers (\%) & 6 \\
\hline Cull plus death rate, cows $(\%)$ & 35 \\
\hline Culled cows sold for dairy (\%) & 4 \\
\hline Culled cows sold for beef $(\%)$ & 25 \\
\hline Infertility, heifers (\%) & 2 \\
\hline Annual mortality, cows (\%) & 6 \\
\hline Annual mortality, heifers (\%) & 2 \\
\hline Mortality, birth to $12 \mathrm{mo}(\%)$ & 3 \\
\hline Benchmark conception rate, heifers (\%) & 60 \\
\hline Benchmark conception rate, lactation 1 (\%) & 40 \\
\hline Benchmark conception rate, later lactations (\%) & 35 \\
\hline Abortion rate, cows (\%) & 5 \\
\hline Abortion rate, heifers $(\%)$ & 2 \\
\hline Dystocia risk bull calves, cows (\%) & 7 \\
\hline Dystocia risk bull calves, heifers (\%) & 24 \\
\hline Dystocia risk heifer calves, cows (\%) & 4 \\
\hline Dystocia risk heifer calves, heifers (\%) & 14 \\
\hline Dystocia risk beef calves, cows (\%) & 8 \\
\hline Loss from dystocia score $>3$, cows $(\$)$ & 80 \\
\hline Loss from dystocia score $>3$, heifers $(\$)$ & 103 \\
\hline Stillbirth risk bull calves, cows (\%) & 8 \\
\hline Stillbirth risk bull calves, heifers (\%) & 20 \\
\hline Stillbirth risk heifer calves, cows (\%) & 4 \\
\hline Stillbirth risk heifer calves, heifers (\%) & 10 \\
\hline Stillbirth risk beef calves, cows (\%) & 8 \\
\hline Dam mortality bull calf, heifers (\%) & 3 \\
\hline Dam mortality heifer calf, heifers (\%) & 2 \\
\hline Discount rate $(\%)$ & 8 \\
\hline Annual veterinary costs (\$/animal) & 60 \\
\hline Veterinary costs above $8,165 \mathrm{~kg}^{2}(\$ / 1,000 \mathrm{~kg})$ & 11 \\
\hline Synchronization costs, Ovsynch (\$/course) & 13 \\
\hline Conventional semen ( $\$ /$ dose $)$ & 15 \\
\hline Beef semen $(\$ /$ dose $)$ & 15 \\
\hline Weight of culled cows (kg) & 635 \\
\hline Price of culled cows $(\$ / \mathrm{kg})$ & 0.99 \\
\hline Cows sold for dairy purpose ( $\$$ /animal) & 1,100 \\
\hline Labor wage $(\$ / \mathrm{h})$ & 8 \\
\hline Baseline genetic gain (\%) & 1 \\
\hline Baseline milk production, yr $1^{3}(\mathrm{~kg} / \mathrm{yr})$ & 7,983 \\
\hline Inseminations before culling $(\mathrm{H})$ & 4 \\
\hline Inseminations before culling (C) & 7 \\
\hline Age of first breeding (mo) & 14 \\
\hline
\end{tabular}

${ }^{1}$ These parameters were set based on the experience of 2 of the authors (G. E. Seidel and W. Wailes).

${ }^{2}$ Veterinary costs associated with high-producing cows. In addition to annual veterinary costs of $\$ 60$ per head, annual production figures per lactation group that average greater than 8,165 $\mathrm{kg}$ per year have an increase in veterinary costs by $\$ 11$ for every additional $1,000 \mathrm{~kg}$. This changes over the course of the $5 \mathrm{yr}$, as each year has increased genetic gain as animals move through the lactation groups.

${ }^{3}$ Second lactations were calculated at $18 \%$ higher than first lactations and third-and-greater lactations were calculated to be $7 \%$ higher than second lactations.

The sensitivity analysis yielded 13 key inputs for the spheres as follows:

- Market variables: milk price, price of corn, price of forage, price of dairy bull calves, dairy heifer price, and beef calf price;
- Technology variables: price premium of sexed semen, genetic gain, sexing accuracy, and effect of sexed semen on conception rate for heifers and cows;

- Management variables: the number of inseminations for which sexed semen is used on cows 
and heifers (first services only, first and second services, or first, second, and third services), and conception rates.

The last step in preparing for data simulation was to determine an appropriate value range for each key input, as shown in Table 3. The ranges came from multiple sources. Market sphere variables: dairy bull calf price, corn price, and forage price were chosen by our experience (G. E. Seidel and W. Wailes). Market variables: milk price, dairy heifer price, and beef bull calf price, were determined from various reports from the Livestock Marketing Information Center (2007-2011). Variables in the technology sphere, sexed semen premium, sex ratio, genetic gain from sexed semen, and the sexed semen's effect on conception rates for cows and heifers were from recent literature (DeJarnette et al., 2008; Garner and Seidel, 2008). The management variable number of inseminations with sexed semen was chosen to be within the profitable ranges (e.g., fourthservice inseminations with sexed semen that would certainly generate a loss, given any condition, were not used).

Budget Model Output. Net present value was used to measure profitability under each scenario because it captures the lag in benefits (higher milk production in later years) as well as higher costs in earlier years. This approach is consistent with previous Monte Carlo studies by Hyde and Engel (2002), Outlaw et al. (2007), and Leuer et al. (2008). Milk production is expected to increase faster over time as heifers born from sexed semen enter the lactation groups. In general, sexed semen shows increasing returns from implementation until stabilizing at a constant return after 5 yr in constant use. At 5 yr, all lactation groups are occupied by some heifers coming from sexed-semen inseminations and the production level will stabilize at new higher gain annually. The key output variable, SSA per cow, was the net present value per cow for a scenario minus net present value per cow for the baseline, discounted at $8 \%$ over 5 yr.

\section{Sensitivity Analysis}

Varying the 13 key input variables with 10 values each would generate many combinations. This proved to be too great a computational challenge to undertake. However, a spreadsheet macro made it possible to draw a large sample subset from possible combinations through Monte Carlo-based simulations (Hyde and Engel, 2002; Leuer et al., 2008). A uniform distribution was applied to draw a representative sample of possible combinations. The uniform distribution ensured an equal chance of selecting variables across the entire domain. An equal chance was representative, as our objective was to represent combinations of variables, not the probability of any particular combinations. Some sample values are irrelevant because they would not exist in nature. However, computing answers for irrelevant ranges did not create a problem for purposes here because these regions are more costly to find and remove than they are to simply estimate and ignore. Removing regions might also inadvertently eliminate an unforeseen case that could occur in the future.

The variable values in each draw were held constant for $5 \mathrm{yr}$ for consistency. A total of 8,000 draws were

Table 3. Key input variable ranges used for uniform distribution in Monte Carlo simulation

\begin{tabular}{|c|c|}
\hline Variable & $\begin{array}{c}\text { Range } \\
\text { (low, high) }\end{array}$ \\
\hline Milk price $(\$ / 1,000 \mathrm{~kg})$ & 220,440 \\
\hline Corn price $(\$ / 1,000 \mathrm{~kg})$ & 96,224 \\
\hline Dairy bull calf price (\$/animal) & 40,120 \\
\hline Dairy heifer calf price (\$/animal) & 160,650 \\
\hline Beef calf price $(\$ /$ animal $)$ & 190,290 \\
\hline Conception rate factor for management ${ }^{1}$ ( $\%$ of benchmark conception rate) & 80,120 \\
\hline Sex ratio with sexed semen $(\%)$ & 84,93 \\
\hline Genetic gain with sexed semen (\% of benchmark genetic gain) & 1,15 \\
\hline Conception rate for cows using sexed semen ${ }^{2}$ (\% of benchmark conception rate) & 75,90 \\
\hline Conception rate for heifers using sexed semen ${ }^{2}(\%$ of benchmark conception rate) & 65,90 \\
\hline
\end{tabular}

${ }^{1}$ Combining this variable with the baseline conception rates from Table 2 yields a realized conception rate of 48 to $72 \%$ for heifers, 32 to $48 \%$ for first-lactation animals, and 28 to $42 \%$ for later-lactation animals for the baseline scenario.

${ }^{2}$ The use of sexed semen changes the conception rate in addition to the management conception rate factor. The results are multiplicative and shift the range of the realized conception rate. For example, a poor manager (conception rate factor of $80 \%$ ) in combination with sexed semen achieving the lowest conception rate factors on heifers and cows $(65$ and $75 \%$, respectively) would essentially shift the realized conception rates down much lower than the baseline. In this example, the realized rates for a poor manager would be $31 \%(0.8 \times 0.65 \times 0.6)$ for heifers, $24 \%(0.8$ $\times 0.75 \times 0.4)$ for first-lactation cows, and $21 \%(0.8 \times 0.75 \times 0.35)$ for later-lactation cows. 
Table 4. Descriptive statistics for simulated data

\begin{tabular}{lc}
\hline Variable & Mean (SD) \\
\hline Net present value compared with baseline: scenario 1 $(\$)$ & $47.64(52.27)$ \\
Net present value compared with baseline: scenario 2 $\$()$ & $72.62(103.3)$ \\
Net present value compared with baseline: scenario 3 $(\$)$ & $-66.12(107.2)$ \\
Milk price $(\$ / 100 \mathrm{~kg})$ & $32.96(6.36)$ \\
Corn price $(\$ / 1,000 \mathrm{~kg})$ & $163(37)$ \\
Forage price $(\$ / 1,000 \mathrm{~kg})$ & $127(10)$ \\
Dairy bull calf price $(\$)$ & $79.49(22.84)$ \\
Dairy heifer calf price $(\$)$ & $406.1(141.7)$ \\
Beef calf price $(\$)$ & $240.1(28.78)$ \\
Conception rate management factor $(\%)$ & $1.002(0.115)$ \\
Inseminations with sexed semen (integer) & $1.994(0.70)$ \\
Sexed semen premium $(\$ /$ dose) & $19.99(1.16)$ \\
Sex ratio with sexed semen $(\%$ female) & $0.885(0.026)$ \\
Sexed semen genetic gain (proportion) & $1.075(0.043)$ \\
Sexed semen conception rate, cows (proportion of benchmark) & $0.824(0.043)$ \\
Sexed semen conception rate, heifers (proportion of benchmark) & $0.776(0.071)$ \\
Number of simulations & 8,000 \\
\hline
\end{tabular}

analyzed in the spreadsheet budget for each scenario. Table 4 shows descriptive statistics for the key variables across all draws.

\section{Regression of Response Surface}

Due to the complexity of the budget models, and the volume of simulation data, finding a unique solution was not possible. For that reason, we summarized the results by estimating a response surface with regression models (ordinary least squares) for net present value as a linear function of the 13 key variables, with a separate model for each scenario. Response surface methodology, introduced by Box and Wilson (1951), explores the relationships between several explanatory variables and one or more response variables. It is an iterative process that searches for an optimum response surface, beginning with simple linear models to explore the nature of the response function for regions where the final factor combination settings maximize the objective (Box and Draper, 2007). In our case, a simple linear model was sufficient. Nonlinear models (second- and third-order response surface methodology) were examined for quadratic and logarithmic forms, and cross-product terms. For each scenario, the linear regression model achieved coefficient of determination values greater than 0.94, and only 3 of these individual nonlinear or cross-product terms increased the coefficient of determination by 0.005 or more.

To make the regression results more useful, we created variable feasibility maps, which are graphical constructs to provide a simple way to describe profitable and unprofitable regions in the space of the 13 variables. The variable feasibility maps (Figure 2) correspond to the Venn diagram presented in Figure 1. By examining these maps, one can more easily identify the impact of changes in one variable at a time and determine conditions where one sexed semen production strategy (scenario) will always or never be superior to the conventional baseline approach. The variable feasibility maps are a powerful tool because they show how much impact a management or technology change can have in a highly dynamic world, and they can eliminate uncertainty about whether they can have an impact in cases of region $\mathrm{A}$ or $\mathrm{C}$.

Building variable feasibility maps involves a graph examining the influence of one key variable at a time, whereas the other 12 variables are set at fixed values. In particular, they allow one to identify and focus on the region in which changes in a key variable could move overall SSA from negative to positive or vice versa, given fixed values of the other 12 variables. For example, the marginal impact of some variable $\mathrm{x}$ could be computed, given that all 12 other variables are set in the least-favorable portion of their domain range; then, the computation could be repeated for a case where the other 12 variables are fixed in the most-favorable portion of their domain.

In these variable feasibility maps, one key input at a time is plotted on the horizontal axis, and the impact on SSA is plotted on the vertical axis. The slope of this line shows the impact of that variable on SSA, given a fixed index of the other 12 variables. Two regions are of special interest: the upper breakeven value where SSA is always above zero (region $\mathrm{C}$ in the Venn diagram) and the lower breakeven value where SSA is always negative (region $\mathrm{A}$ ). The region between these 2 lines represents the space where the variable of interest could have an impact on whether SSA is positive or negative (region B). That is, region B in the variable feasibility maps shows the only opportunity for an impact on the part of a decision maker. 


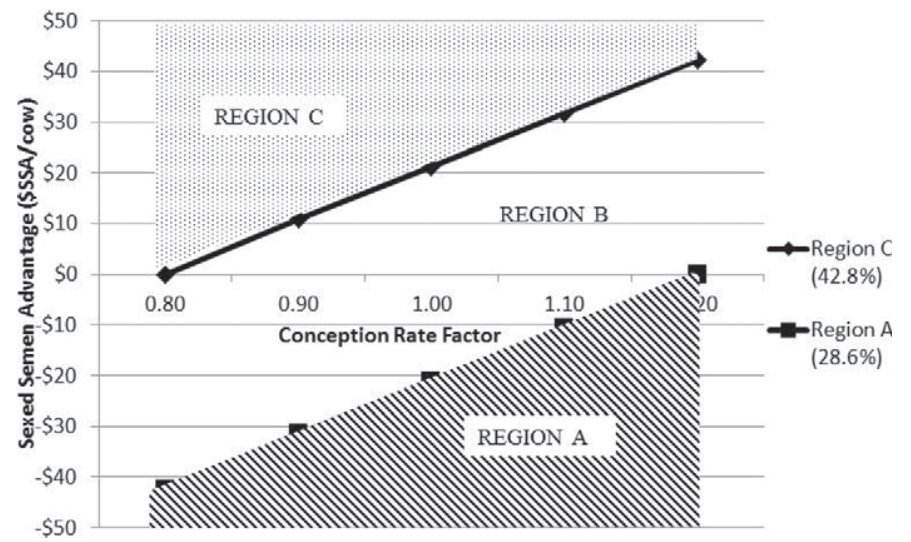

Figure 2. Example of a variable feasibility map: conception rate management variable in scenario 1 . This figure is an example from our results. Any of the variables can be made into a variable feasibility map for any of the scenarios. The larger region B is, the more impact the variable has in controlling positive or negative sexed semen advantage (SSA). The conception rate factor is indicative of the management's ability to impregnate animals. A value of 1.0 indicates that the manager is at the level of the benchmark in terms of conception rates. The $\mathrm{x}$-axis plots the range of the conception rate factor. The linear lines are found using the index levels holding the other variables constant. Via the regression equation, the region A line was found by using linear interpolation and setting SSA to zero when the conception management variable is 1.2 (maximum range value). Therefore, the other values in reference to the indexing had to be set to a level of $28.6 \%$ (of their maximum value in their range) in order for everything below that line to have a negative SSA. Once the $28.6 \%$ was found, the conception rate factor was varied along its range, creating the boundary for region A. Region $\mathrm{C}$ was found the same way, but index values in this case are so that regardless of the conception rate factor value, all outcomes will have a positive SSA. In this case, there is an SSA when the conception rate factor is 1.2 as long as the other key variables are not greater than $28.6 \%$ of the maximum value in their range. There is always an SSA when the factor is as low as 0.80 and the other key variables are at least $42.8 \%$ of their range maximum Region A corresponds to the Venn diagram (Figure 1a) where none of the circles overlap at all. This environment is indicative of no change in the variable of interest and can result in sexed semen producing a better profit than without using sexed semen. Region B corresponds to the Venn diagram (Figure 1b) where all 3 circles partially overlap. This is the most important environment for the variable of interest. In this environment, the variable of interest will determine if the dairy will be more profitable with or without sexed semen, depending on where that variable is in its range. Region $\mathrm{C}$ corresponds to the Venn diagram (Figure 1c) where all 3 circles overlap entirely. A change in the variable of interest will not result in a negative SSA in the given scenario. Dairies operating in this given environment will profit using sexed semen more than without it across the entire range of the variable of interest because the other variables favor sexed semen in such a way that the variable of interest cannot move the outcome to the negative region.

The fixed value chosen to parameterize 12 variables in the resulting regression is set by indexing each variable by quartiles along its normalized range from 0 to $100 \%$ (see Table 3), with $100 \%$ being the absolute best condition for sexed semen and $0 \%$ indicating the variables at the worst condition for sexed semen. An index of $75 \%$, for example, means that variables with a positive effect were set at their numerical upper quartile and variables with a negative effect were set at their numerical lower quartile. The dividing lines between regions $\mathrm{A}$ and $\mathrm{B}$ and $\mathrm{B}$ and $\mathrm{C}$ correspond to a breakeven index value chosen for the other 12 variables. For simplicity and exposition, all 12 variables were indexed at the same level, and then the breakeven high and low values were computed for the remaining variable of interest. For example, the breakeven upper bound between $\mathrm{B}$ and $\mathrm{C}$ might be $78 \%$. This would mean that all 12 variables have to be set at, or above, their corresponding index value of $78 \%$ before the variable of interest could return a positive SSA at its lowest indexed value. Conceptually, a value of $78 \%$ could be considered insensitive, as it only has an impact when all other variables are generally favorable (higher than 78 percent). Had the index been $38 \%$, this variable would be more important, as it would be influential even when other conditions are not favorable.

\section{RESULTS AND DISCUSSION}

The simulated raw data from the Monte Carlo draws produced about 160,000 pieces of information for each scenario: 13 variables, 5 yr of profit, net present value, and SSA, each with 8,000 draws, totaling 160,000 [8,000 $\times(13+5+1+1)]$. Figure 3 displays histograms contrasting the distribution of the SSA across scenarios, measured as the difference net present value per cow of each scenario versus the conventional baseline. Scenario 1 had the most consistently positive SSA. Scenario 2 was typically also advantageous, with over $70 \%$ of simulations giving a positive SSA compared with only $25 \%$ in scenario 3 . Scenario 3 had the widest variation, ranging from less than $(-\$ 300)$ to over $\$ 200$ SSA per cow. The maximum for scenario 3 was $\$ 259$ SSA per cow. Scenario 1 had the smallest spread, ranging from a minimum of $-\$ 78.11$ to a maximum of $\$ 227$ SSA per cow. Scenario 2 had the highest maximum, reaching $\$ 373.59 \mathrm{SSA} /$ per cow.

The higher maximum in scenario 2 stems from the large price difference that can occur between dairy heifer calf prices and dairy bull calf prices. Scenario 2 allows for faster genetic improvement of replacements and the ability to produce more heifer calves. In scenario 1, a larger proportion of the herd is given conventional semen. The void between heifer calves produced from sexing and the replacement needs of the whole herd falls to the unsexed calves born from the cows. This results in fewer heifer calf sales, indicated by a lower maximum than in scenario 2 . In scenario 3 , dairy heifer calf price has a very different effect. When dairy heifer prices are high, the control farm has the advantage over scenario 3, given that the differential between beef calves and dairy heifer calves can be very 


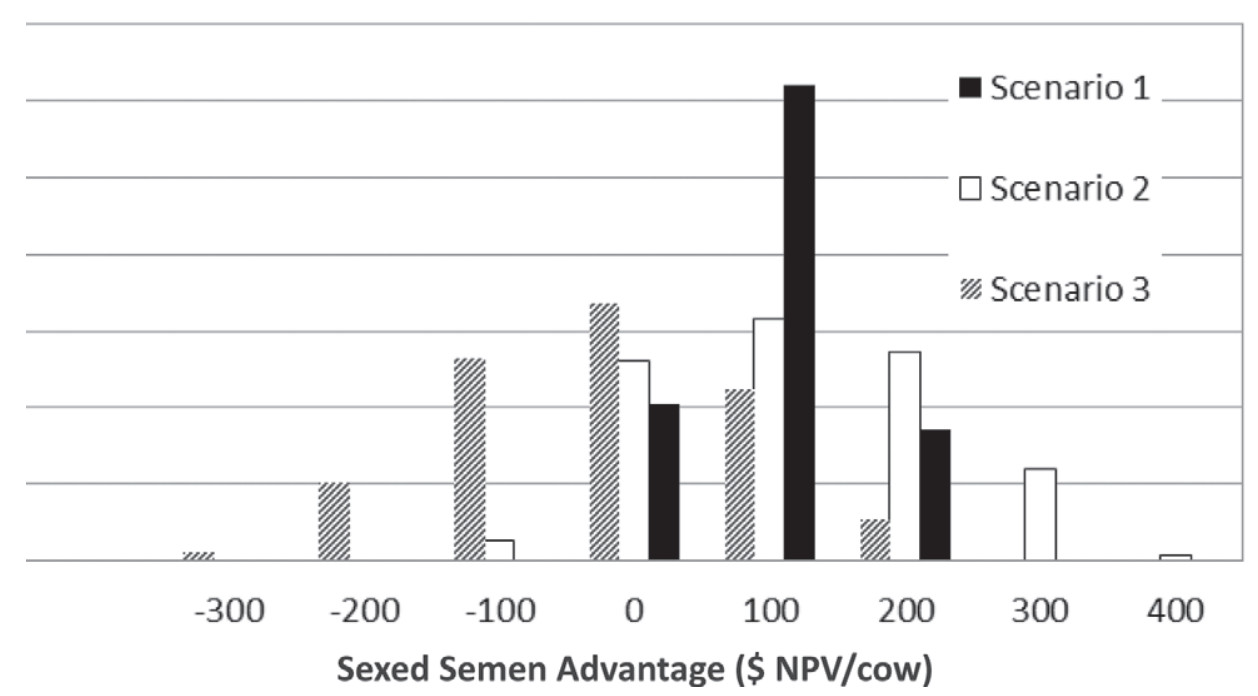

\section{0}

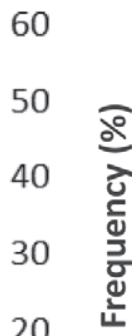

Figure 3. Histogram of sexed semen advantage (SSA) distribution by scenario. Scenarios 1 through 3 refer to the breeding scenario using sexed semen. Scenario 1: sexed semen is only used on heifers. Scenario 2: sexed semen is used on heifers and the genetically superior cows, where nonreplacement animals are given conventional dairy semen. Scenario 3: sexed semen is used on heifers and genetically superior cows, where nonreplacement animals are given conventional beef semen. NPV $=$ net present value.

large. However, if dairy bull calf prices are low, beef calf prices can have an advantage, as both heifer and bull crossbred calves will sell at a premium to dairy bull calf prices. The degree of the advantage, however, is smaller when heifer prices are high compared with beef. The majority of positive SSA results in scenario 3 are from a beef calf price advantage.

The results from the regression analysis of the simulation data appear in Table 5. In the regression model for scenario 1, variables with sizeable predicted positive effects on SSA include dairy heifer price, the sexed semen conception rate for heifers, the conception rate management factor, the number of inseminations with technology, and the sex ratio with sexed semen. The relative importance of effects can be determined from the estimates of the regression coefficients in Table 5 . On this basis, a $\$ 100$ increase in dairy heifer price is predicted to increase SSA by about $\$ 32$. A $0.10 \mathrm{im}-$ provement (e.g., 1.00 to 1.10 , which is equivalent, for example, to increasing benchmark conception rates of 30 to $33 \%$ pregnant) in overall conception management would increase SSA by about $\$ 11(0.10 \times$ the regression coefficient of 105.9 in Table 5 ), and a 5 percentage points improvement in sexed semen's negative effect on heifer conception rate (e.g., from 75 to $80 \%$ of the conventional semen pregnancy rate) would increase SSA by about $\$ 10(0.05 \times$ the regression coefficient of 212.9 in Table 5). A 2 percentage points improvement in the sexed semen sex ratio (e.g., from 0.90 to 0.92 ) would offer about a $\$ 6$ increase in SSA. Relative to real-world feasible changes in values of predictors, none of the predictors had dramatic negative effects on profitabil- ity. For example, even a $\$ 20$ increase in dairy bull calf price (larger relative to its feasible range than the $\$ 100$ change in dairy heifer calf price) would be predicted to lower SSA by only about $\$ 6$. Worth noting is that neither feed prices nor the sexed semen premium had substantial predicted effects on SSA. Also, due to lower conception rates with sexed semen the more it is used, the less milk will be produced because of the delays in getting cows pregnant. This is the reason for the negative regression coefficient for milk price in Table 5. Although this coefficient is statistically significant, the effects are small. Even an $\$ 11 / 100 \mathrm{~kg}$ increase in milk price would result in less than $\$ 8$ change in SSA.

Of course, these results must be taken with caution. The use of sexed semen under conditions of poor or marginal management, for example, could be problematic. If baseline conception rates were poor (e.g., $48 \%$ for heifers), sexed semen conception rates were only $70 \%$ of those poor rates, and the sexed semen were used for first, second, and third services, heifers would be much older when conceiving than with conventional semen, and many would be inappropriately culled as infertile after the fourth service.

Under scenario 2, many of the same variables had positive effects, as large as and sometimes much larger than under scenario 1. A $\$ 100$ increase in dairy heifer price under scenario 2 was predicted to increase SSA by $\$ 68$; a $10 \%$ improvement in conception rate management (e.g., from benchmark conception rates of 30 to $33 \%$ ) was associated with an increase in profitability of $\$ 19$ and a 2 percentage points improvement in the sexed semen sex ratio, about an increase of $\$ 11$; these 
Table 5. Slope coefficient values (SE in parentheses) from regression of difference in net present value difference from not using sexed semen on key variables, by scenario, with 8,000 observations per scenario

\begin{tabular}{lccc}
\hline Variable & Scenario 1 & Scenario 2 & Scenario 3 \\
\hline Milk price $(\$ / 100 \mathrm{~kg})$ & $-0.38(0.102)^{* * *}$ & $-1.60(0.117)^{* * *}$ & $-1.58(0.175)^{* * *}$ \\
Corn price $(\$ / 1,000 \mathrm{~kg})$ & $-13.83(5.54)^{*}$ & $-10.29(5.20)$ & $-8.68(7.14)$ \\
Forage price $(\$ / 1,000 \mathrm{~kg})$ & $0.0001(0.001)$ & $0.0034(0.002)$ & $-0.0027(0.002)$ \\
Dairy bull calf price $(\$)$ & $-0.315(0.00586)^{* * *}$ & $-0.675(0.00672)^{* * *}$ & $-1.840(0.01000)^{* * *}$ \\
Dairy heifer calf price $(\$)$ & $0.321(0.000944)^{* * *}$ & $0.679(0.00108)^{* * *}$ & $-0.541(0.00161)^{* * *}$ \\
Beef calf price $(\$)$ & $105.9(1.165)^{* * *}$ & $187.4(1.338)^{* * *}$ & $1.654(0.00794)^{* * *}$ \\
Conception rate management factor & $10.37(0.190)^{* * *}$ & $9.531(0.218)^{* * *}$ & $110.6(1.989)^{* * *}$ \\
Number of inseminations with sexed semen & $-2.176(0.116)^{* * *}$ & $-5.785(0.133)^{* * *}$ & $-5.68(0.325)^{* * *}$ \\
Sexed semen premium $(\$ /$ dose) & $279.6(5.143)^{* * *}$ & $570.3(5.905)^{* * *}$ & $569.6(8.780)^{* * *}$ \\
Sex ratio with sexed semen & $29.08(3.082)^{* * *}$ & $29.83(3.539)^{* * *}$ & $30.17(5.263)^{* * *}$ \\
Sexed semen genetic gain (proportion) & & $254.8(3.547)^{* * *}$ & $316.0(5.274)^{* * *}$ \\
Sexed semen conception rate, cows & & $214.7(2.154)^{* * *}$ & $216.8(3.202)^{* * *}$ \\
(percent of unsexed semen benchmark) & $212.9(1.875)^{* * *}$ & $-1,142(8.289)^{* * *}$ & $-1,104(12.32)^{* * *}$ \\
Sexed semen conception rate, heifers & & 0.982 & 0.964 \\
(percent of unsexed semen benchmark) & $-582.8(7.218)^{* * *}$ & 0.948 & \\
Constant & & & \\
$\mathrm{R}^{2}$ & & &
\end{tabular}

*** $P<0.001 ;{ }^{*} P<0.05$.

effects are about twice as large as their corresponding effects under scenario 1. As might be expected, the sexed semen effect on conception rate for cows is important in scenario 2 , with an improvement of 3 percentage points in that rate being predicted (e.g., from 0.82 to 0.85 of the conventional semen pregnancy rate) to bring about an $\$ 8$ increase in SSA. A 5 percentage points increase in the effect of sexed semen on heifer conception rate offers about a $\$ 10$ increase in SSA, and one more insemination with sexed semen about a $\$ 10$ increase (both about the same as in scenario 1). As in scenario 1 , few predictors had substantial predicted negative effects, although they were somewhat larger in absolute terms under scenario 2. An increase in dairy bull calf price of $\$ 20$ would be predicted to lower SSA by $\$ 14$, about twice as much as under scenario 1 .

Scenario 3 shows some effects similar to scenario 2, but also some that are larger in absolute terms and in the opposite direction. The predicted positive influence of the sex ratio achieved with sexed semen and the sexed semen effect on conception rate for cows and heifers were essentially identical to those found in scenario 2. However, where an interesting difference appeared was in the influence of dairy calf prices. Under scenario 3 , increases in dairy heifer calf price are predicted to have a large and negative rather than positive effect on differences in profit: about a $\$ 54$ loss in SSA for a $\$ 100$ increase in calf price. Dairy bull calf price under scenario 3 also has large negative effect, with a $\$ 20$ increase in price being associated with a predicted $\$ 36$ decrease in SSA, almost triple its negative effect under scenario 2 . Beef calf price, as might be anticipated, also mattered considerably, with a $\$ 20$ increase being predicted to bring about a $\$ 32$ increase in SSA, whereas this is irrelevant under scenario 1 or 2 . The number of inseminations with sexed semen also had a sizeable and different effect, with one more insemination predicted to offer an almost $\$ 20$ improvement in SSA under scenario 3, about triple what was predicted under scenario 1 or scenario 2 . The conception rate management factor is less influential in scenario 3 than scenario 2 , offering about the same $\$ 11$ increase in SSA for a $10 \%$ increase in this factor as was found in scenario 1 (both about half of what was found in scenario 2).

\section{Variable Feasibility Maps}

Index values corresponding to variable feasibility maps for all 13 variables (values dividing regions $\mathrm{A}$, $\mathrm{B}$, and $\mathrm{C}$ ) were calculated and an example is shown in Figure 2. For each variable and scenario, a break-even line was calculated using an upper and lower bound using the regression equation in Table 5 . Using the index values, an upper and lower boundary was set such that everything below the lower bound would result in negative SSA (region A) and everything above the upper bound would result in positive SSA (region C). The space between the upper and lower bounds represents the range over which the variable of interest could influence SSA from being positive or negative; that is, it represents the size of region B. For example, the milk price coefficient was negative in the regression, so a higher milk price reduces SSA. Milk price in scenario 1 has a lower boundary break-even index of $37.4 \%$, meaning that when milk price is at its maximum value, the other variables have to be at an index level of at least $37.4 \%$ before a lower milk price can lift SSA out of region $\mathrm{A}$ and into region $\mathrm{B}$. The same concept applies 
for region C. An upper index level of $37.9 \%$ indicates that when milk price is at its minimum, SSA will always be positive if all the other variables are indexed at or above $37.9 \%$. For milk price, region B has a very small range of $0.53 \%$. For every index level within that range, milk price will be the deciding factor in the sign of SSA. Otherwise, profitability of sexed semen is not sensitive to milk price. As mentioned above, one of the values of the variable feasibility maps is that it can, as it has here, provide information about profitability over a wide range of potential changes. In this case, milk price will not change the advantage of sexed semen; if other factors are more favorable than $37.9 \%$, SSA will be positive. If they are all less than $37.4 \%$, sexed semen will not increase profits.

In scenario 1 all of the index percentages for region A lie below $40 \%$, indicating that conditions would need to be poor in general to create a situation where sexed semen always would be less profitable than the control. Interestingly, for region $\mathrm{C}$, the majority of percentages are below $50 \%$, indicating that any of the variables would make sexed semen better in unfavorable conditions. Dairy heifer price is the only variable in this section to have an upper region greater than $50 \%$. Dairy heifer price does not have a region $\mathrm{A}$, meaning that even if all 12 other variables are set at an index of $25 \%$ or below, regions of profitability still exist. Variables with a larger difference in region B indicate steeper slopes and a greater ability to change the outcome. Consequently, the variables with the largest capabilities for manipulating the outcomes are the effect of sexed semen on conception rates in heifers, dairy management's effect on conception rates, and dairy heifer price.

In scenario 2 all percentages indicate that the floor is also below 40\%; however, in this scenario, the ceiling for most variables is somewhat higher. Variables indicating the greatest impacts on the comparative investment are management's effect on conception rates, the effect of sexed semen on heifers, dairy bull calf price, and the sex ratio. Smaller values in region B indicate less opportunity to change profitability given the conditions.

In scenario 3, both region $\mathrm{A}$ and $\mathrm{C}$ percentages are much higher. This indicates that most variables need to be in a good position for sexed semen to be profitable. Scenario 3 is the only scenario where it is advantageous for heifer price to be low, indicated by the negative slope in the regression. Producing heifers for replacements, and beef calves for the other calves, is only advantageous if heifer price is not a lot higher than beef calf prices and beef calves fetch a much higher price than dairy bull calves. The variables in this scenario with the largest impact are beef calf price, dairy bull calf price, and dairy heifer calf price. Dairy heifer calf price does have a region C. However, it's also moving in the opposite direction to the other 2 scenarios.

Several conclusions can be drawn by looking more holistically at each scenario. Scenario 3 has the smallest total region $\mathrm{B}$ for all the variables, indicating the least influence from the instrument variables. Scenario 3 had the least amount in region $\mathrm{C}$ and the highest in region A. Scenario 1 has the largest area in region $\mathrm{C}$ and the least in region $\mathrm{A}$, making it a safer option compared with scenarios 2 and 3 .

Another feature of the index values is they show how high or low other variables need to be for sexed semen to always be profitable or unprofitable, respectively. The high and low index values for regions A, B, and $\mathrm{C}$, in each scenario define boundaries that can be used to make sweeping judgments about any particular variable. For example, the most influential variable in all 3 scenarios is dairy heifer price. The range in region A, scenario 1 , is from 25.9 to $37.4 \%$. This high and low translate into dairy heifer prices of $\$ 286.80$ and $\$ 343.26$, respectively. As $\$ 286.80$ is the lowest index value for region $\mathrm{A}$, we can say that all variables will be in region $\mathrm{A}$ if dairy heifer price is below $\$ 286.80$; likewise, as $\$ 343.26$ is the highest index value, we can say that all variables will be in region $B$ if heifer price is above $\$ 343.26$. Between these 2 values, some variables will be in region $\mathrm{A}$ and some in region $\mathrm{B}$.

For region $\mathrm{C}$ in scenario 1, the minimum is $37.4 \%$ and the maximum is $40.5 \%$. These translate to $\$ 343.26$ and $\$ 358.45$ as values for heifer calves. Between these 2 values, some variables are in region $\mathrm{B}$, and some are in region C. Above $\$ 358.45$, all the other variables in scenario 1 are in region C. Similarly, in scenario 2, with a heifer calf price above $\$ 354.04$ (index of $39.6 \%$ ), all other variables will be out of region A. A price of $\$ 379.52$ and above will put all other variables into region C. In scenario 3, dairy heifer price moves in the opposite direction. For all other variables to be out of region A, the dairy heifer price must be below $\$ 449.27$ and for all the other variables to be in region $\mathrm{C}$, the price has to be below $\$ 299.16$.

The index levels can act as a guide to which scenario is the best choice based on dairy heifer price. Rounding to the nearest $\$ 25$ increment, if the price for heifer calves is below $\$ 300$, scenario 3 is most likely to have positive outcomes. When prices are $\$ 300$ to $\$ 350$, scenario 3 will be more likely to have positive outcomes. When prices are $\$ 350$ to $\$ 375$, scenario 1 is the most likely to have positive outcomes. Finally, when prices are $\$ 375$ and above, scenario 1 and 2 are more likely to have positive outcomes, and scenario 3 will have some positive values. These prices are in broad agreement with Seidel (2003) who concluded that if the differ- 
ence between values of dairy heifer and bull prices were $\$ 300$, the break-even extra cost of sexed semen that farmers could afford varied between $\$ 25.46$ and $\$ 43.52$, depending on the fertility of the sexed semen.

\section{Summary}

We successfully fit a response surface to a wide range of values for 13 key input variables in 3 influence spheres for dairy: (1) the market, (2) management practices, and (3) technological efficiency. The same was done for 3 management scenarios: (1) sexed semen used on heifers only, (2) sexed semen used for replacements on cows and heifers (nonreplacement breeders are inseminated with conventional dairy semen), and (3) sexed semen used for replacements on cows and heifers (nonreplacement breeders are inseminated with conventional beef semen).

An interesting result stemming from the variable feasibility maps was that the window of influence for most instrument variables is very small. That is, each of the 13 key influence variables could tip the feasibility scales toward or away from sexed semen for a small window of conditions for the other 12 variables, measured as an index from poor (0) to good (100). Many index values are less than ideal for sexed semen to be a positive investment. Nevertheless, most scenarios could overcome conditions a little worse than average (less than an index of 50\%) to make an investment positive. That is, sexed semen will be profitable for most conditions under the control of managers and technicians when the favorability of the other 12 variables measured here are average or better.

Most conclusively, the differential between dairy heifer calf price and beef calf price is the driving variable for SSA. In terms of magnitude, a high heifer price will make scenario 3 infeasible, resulting in large losses due to forgone opportunities that can be made by raising excess heifers for the purpose of sale. Region A is larger for most variables, and region $\mathrm{C}$ is smaller for most variables.

The most obvious limitation of this work is the static nature of the model compared with the dynamic nature of the dairy farm. Simplifications in programming had to be made, and to capture the fiscal values annually, totals and aggregates for the whole year were used to quantify changes. Annual profit works well to calculate sexed semen's potential impacts, but does not capture the cyclical nature and dynamics of a dairy farm. Even with the programming of a more dynamic model, totals and aggregates would still be required to develop a measure of standard fiscal quantity, even if annual profit was not used.

\section{CONCLUSIONS}

The results validate that key input values affected the feasibility of each strategy differently and that variable ranges existed in which a decision maker in one sphere could not change the profitability of sexed semen, given what was occurring in the other 2 spheres. Therefore, cooperation between technology providers and farm managers could enhance the chance of sexed semen being more profitable than conventional methods. Results from the response surface showed that scenario 2 was generally the most profitable, followed by scenario 1 . Scenario 3 was profitable only under a narrow set of circumstances. Scenario 2 was generally more profitable than scenario 1 because more heifers were available for sale. Likewise, heifer calf sales were lower in scenario 1 because a larger part of the herd was required for heifer replacements. Scenario 2 was typically better than scenario 3 as well, unless beef prices were high relative to dairy calf prices. Scenario 3 was profitable when dairy calf prices were low compared with beef prices. Sexed semen appears to work best for replacements but is too expensive to use for nonreplacements. Targeting heifers first, but also using sexed semen on cows is more profitable than trying to regulate sex only in heifers. Finally, a producer should target nonreplacements to beef or dairy based on expected relative prices.

\section{ACKNOWLEDGMENTS}

This project was supported by National Research Initiative Competitive Grant no. 2006-55203-17390 from the USDA National Institute of Food and Agriculture (Washington, DC).

\section{REFERENCES}

Box, G. E. P., and K. B. Wilson. 1951. On the experimental attainment of optimum conditions. J. Roy. Statist. Soc. B 13:1-45.

Box, G. E. P., and N. R. Draper. 2007. Response Surfaces, Mixtures and Ridge Analysis. 2nd ed. Wiley-Interscience John Wiley and Sons Inc. Hoboken, NJ.

De Vries, A., M. Overton, J. Fetrow, K. Leslie, S. Eicker, and G. Rogers. 2008. Exploring the impact of sexed semen on the structure of the dairy industry. J. Dairy Sci. 91:847-856.

DeJarnette, J. M., R. L. Nebel, C. E. Marshall, J. F. Moreno, C. R. McCleary, and R. W. Lenz. 2008. Effect of sex-sorted sperm dosage on conception rates in Holstein heifers and lactating cows. J. Dairy Sci. 91:1778-1785.

Garner, D. L., and G. E. Seidel Jr. 2008. History of commercialized sexed semen for cattle. Theriogenology 69:886-895.

Herbst, B. K., D. P. Anderson, J. L. Outlaw, J. W. Richardson, and T. Bilby. 2009. The effects of sex-sorted semen on southern dairy farms. Southern Agric. Econ. Assoc. Ann. Mtg., Selected paper. Accessed July 15, 2011. http://purl.umn.edu/46814.

Hohenboken, W. D. 1999. Applications of sexed semen in cattle production. Theriogenology 52:1421-1433.

Hyde, J., and P. Engel. 2002. Investing in a robotic milking system: A Monte Carlo simulation analysis. J. Dairy Sci. 85:2207-2214. 
Khanal, A. R., and J. M. Gillespie. 2011. Adoption and profitability of breeding technologies on United States dairy farms. Southern Agric. Econ. Assoc. Ann. Mtg., Selected paper. Accessed July 15, 2011. http://purl.umn.edu/98574.

Leuer, E. R., J. Hyde, and T. L. Richard. 2008. Investing in methane digesters on Pennsylvania dairy farms: Implications of scale economies and environmental programs. Agric. Resource Econ. Rev. 37:188-203.

Livestock Marketing Information Center. 2007-2011. Price spreadsheets and tables. Accessed May 25, 2011. http://www.lmic.info.

Martins, J. P. N., R. K. Policelli, L. M. Neuder, W. Raphael, and J. R. Pursley. 2011. Effects of cloprostenol sodium at final prostaglandin $\mathrm{F}_{2 \alpha}$ of Ovsynch on complete luteolysis and pregnancy per artificial insemination in lactating dairy cows. J. Dairy Sci. 94:2815-2824.

Norman, H. D., J. L. Hutchinson, and R. H. Miller. 2010. Use of sexed semen and its effect on conception rate calf sex, dystocia, and stillbirth of Holsteins in the United States. J. Dairy Sci. 93:3880-3890.

Olynk, N. J., and C. A. Wolf. 2007. Expected net present value of pure and mixed sexed semen artificial insemination strategies in dairy heifers. J. Dairy Sci. 90:2569-2576.

Outlaw, J. L., L. A. Ribera, J. W. Richardson, J. da Silva, H. Bryant, and S. L. Klose. 2007. Economics of sugar-based ethanol production and related policy issues. J. Agric. Appl. Econ. 39:357-363.

Schenk, J. L., D. G. Cran, R. W. Everett, and G. E. Seidel Jr. 2009 Pregnancy rates in heifers and cows with cryopreserved, sexed sperm: Effects sperm numbers per inseminate, sorting pressure and sperm storage before sorting. Theriogenology 71:717-728.

Seidel, G. E., Jr. 2003. Economics of selecting for sex: The most important genetic trait. Theriogenology 59:585-598.

Seidel, G. E., Jr., and D. L. Garner. 2002. Current status of sexing mammalian spermatozoa. Reproduction 124:733-743. 